\title{
Older people in care homes and the primary care nursing contribution: a review of relevant research
}

Claire Goodman and Rosemary J Woolley Primary Care Nursing Research Unit, University and King's Colleges, London, UK

In the UK, older people who are resident in care homes because of their needs for social support and personal care receive their health care from primary health care. Although there is increasing input from district nurses in care homes (Audit Commission, 1999), there is little knowledge or recognition of the primary care nursing contribution. This paper reviews two types of research literature: studies that consider the health care needs of older people in residential care homes that could inform nursing support and interventions in care homes, and research that describes the nursing involvement with these settings. The paper argues that on the basis of the research reviewed many of the health problems older people in care homes experience could be avoided or improved by primary care nursing support and intervention. A reassessment is needed of how the interface between community and residential care is managed so that older people in care homes have access to appropriate health care support.

Key words: care homes; district nurses; older people; primary care nursing; primary health care; residential homes

\section{Introduction}

In the UK, older people who are resident in care homes because of their needs for social support and personal care receive their health care from primary health care. There is evidence that the impact of providing general practitioner (GP) services to older people in institutional settings is greater than providing for older people in their own homes (Jacobs, 2003; Kavanagh and Knapp, 1998; Pell and Williams, 1999). However, there is little discussion of the contribution of other primary care based NHS practitioners who regularly work with care homes and what kind of interventions they undertake for older people in these settings. This is despite an increasing policy expectation that NHS staff will work closely with other providers

Address for correspondence: Dr Claire Goodman, Primary Care Nursing Research Unit, University and Kings College's London, UCL Archway Campus, Holborn Union Building Level 2, Highgate Hill, London N19 3UA, UK. Email: c.goodman@pcps.ucl.ac.uk of care for older people and that care homes will offer intermediate care and rehabilitation services alongside their long term care provision (Department of Health, 2001a). The aim of this paper is twofold. To review evidence of the health needs of older people in care homes that could benefit from primary care nursing interventions and support, and to establish what is already known about the nursing contribution in these settings.

\section{Care home provision for older people}

In England, care homes provide for older people who have been assessed as needing ongoing help with personal and/or nursing care. Some care homes can provide both types of care, but the majority differentiate between residential (personal/ social care) and nursing care. Most care homes in England (71\%) offer residential and personal care only, and the independent sector is the main provider of $90 \%$ of these homes. In 2000 there were 
341200 places in homes offering residential care (Department of Health, 2000). Of the total population who are over $65,4 \%$ are resident in care homes and from age 75 this progressively rises with $30 \%$ of people aged over 90 resident in care homes (Wanless, 2001).

In April 2002, the Care Standards Act (Department of Health, 2001a) replaced the Registered Homes Act 1984 as the legal framework for regulation of care services. The Care Standards Act led to changes in the definition of and regulatory arrangements for care homes for older people in England and Wales. The Act makes no distinction in registration between residential and nursing homes, stating that an establishment is a care home if it provides accommodation together with nursing and/or personal care. For the purposes of this review, the definition of care home, unless otherwise stated, applies to those who largely provide personal rather than nursing care to residents.

\section{The review}

The review located studies on the health needs of older people in care homes that could arguably inform nursing intervention and support for this population, and research that considered specifically the primary care nursing contribution to care homes. Databases included were: CINAHL, MEDLINE, BIDS, AgeInfo, the Cochrane Library and British Nursing Index. Variations and combinations of key words used included residential homes, long-term care, older people, health needs assessment, nursing, and primary health care. Studies were excluded if the two reviewers independently considered the research focus unlikely to inform nursing work in care home settings (e.g. specific medical conditions or therapy regimes). The research literature was organized into three areas: research on physical and mental health needs, research on the experience of being a resident and research into the nursing contribution. Studies that included both residential and nursing homes were included. Literature was reviewed from 1990, as the NHS and Community Care Act (Department of Health, 1990) was the last significant change in the organization and funding of support for care homes (residential) up until the implementation of the National Minimum Care Standards Act in 2002 (Department of Health, 2001a).

\section{The research evidence: older people in residential homes}

\section{Research into health care needs}

In the wake of the reforms of the NHS and Care in the Community Act (Department of Health, 1990), a series of research studies looked at dependency levels in relation to costs and quality of life (Personal Social Services Research Unit (PSSRU), 2001). A longitudinal survey of 2544 people admitted to publicly-funded residential and nursing home care in 1995 and a cross-sectional survey of residents ( $n=11899$ ) was carried out in 1996 . The results showed that residents are considerably more dependent than a decade ago, particularly with regard to cognitive impairment and inability to perform self-care tasks such as washing. In private or voluntary residential homes the proportion of people who are highly dependent had risen by $28 \%$. Crosby et al. (2000) in a separate survey of 468 residents found that $20 \%$ of residents in the residential and dual-registered homes were classified in the highest dependency category. Like the Personal Social Services Research Unit (PSSRU) research, they found that although nursing homes have the highest dependency levels, there is a band of overlap between the dependency ratings of residents in residential and nursing homes.

These studies claim that residential homes are supporting residents with greater disability than previous surveys indicate. However, it is acknowledged that comparison of studies is difficult when different measures of dependency have been employed. These include the DHSS classification of dependency (Davies and Knapp, 1978), the Barthel Activities of Daily Living Index (Mahoney and Barthel, 1965), the Clifton Assessment Procedures for the Elderly (Pattie and Gilleard, 1979) and the modified Crichton Royal Behavioural Rating Scales (Wilkin and Jolley, 1979). The concept of dependency has also been unclear (Dant, 1988; Darton, 1994). Challis et al. (2000) in their survey $(n=308)$ provide evidence that admission is as influenced by economic factors as by health or social need, and defined the majority $(71 \%)$ of new admissions to residential homes as having low dependency needs. Nevertheless, the evidence suggests that new admissions to residential care are increasingly old (aged 80 or over) and that a minority are severely dependent (Challis et al., 2000; Crosby et al., 2000). 


\section{Specific health needs: identification and management}

It is argued that older people resident in care homes feature many clinical diagnoses, including nonstroke cardiovascular disorder, rheumatological diseases, dementia, stroke and neurodegenerative disease (Challis et al., 2000; Royal College of Physicians et al., 2000). More research, however, has focused on the prevalence and management of specific health needs such as continence (Peet et al., 1995; 1996; Roe and Shiels, 2000), infection (Yates et al., 1999), pressure sores (Shiels and Roe, 1999), hip fracture (Butler et al., 1996; Norton et al., 1999), dental health (Lall, 1999), diabetes (Taylor and Hendra, 2000), visual problems (Sturgess, 1994), hearing impairment (Stumer et al., 1996), and terminal care (Komaromy et al., 2000) - all of which are relevant to nursing. It is difficult to generalize from these studies which have been few, of a small sample size, have not all been carried out in the UK or do not differentiate between residential and nursing home populations. Nevertheless, they indicate prevailing health needs that are inconsistently managed and that could be improved through nursing support collaboration with unqualified staff. For example, two separate surveys by Peet et al. (1995) $(n=6079)$ and Roe and Shiels (2000) $(n=652)$ found that around a third of residents from residential homes had a continence problem. Eighty seven per cent of homes in the Peet et al. (1996) survey reported using aids and appliances. Both studies claimed that in only two-thirds of the homes was promotion or management of continence adequate. Komaromy et al. (2000) found that although care staff were committed to providing quality terminal care for residents, barriers to good practice included staff shortages, a lack of knowledge of palliative care and the physical layout of the home.

\section{Mental health needs}

High levels and comorbidity of cognitive impairment, depression, dementia and behavioural problems have been identified by several studies in care homes (Godlove Mozley et al., 2000; Jagger and Lindesay, 1997; Medical Research Council Cognitive Function and Ageing Study, 1999). Jagger and Lindesay (1997) found that in a population of 6079 living in different types of residential facilities, $38 \%$ were moderately or severely cognitively impaired and behavioural problems were present in $11.5 \%$. The research conducted by Challis and colleagues (Godlove Mozley et al., 2000) identified clinically significant cognitive impairment in $61 \%$ of new admissions to the 18 residential homes in their sample, and nearly $45 \%$ were classified as 'depression cases'. Comorbidity of cognitive impairment and depression was found in $24 \%$ of the residents and positive associations were found between cognitive impairment and dependency, depression and reduced mobility, and depression and social class. Depression in particular has been identified as a major health threat for older people in residential homes (Ames, 1990). However, it has been argued that an awareness of depressive disorders in this population is poor and symptoms of depression often go unrecognized by care staff (Bagley et al., 2000). The available evidence suggests that mental health conditions are common, that they may mask other physical problems such as pain, are a challenge for assessment and indicate a need for specialist expertise for this population (Godlove Mozley et al., 2000).

\section{Intervention-based studies}

A few intervention studies have targeted the specific needs of older people living in residential homes with varying success. These have included the introduction of specialist outreach teams for care homes to improve the quality of resident staff interaction, and resident mental health (Proctor et al., 1999; Reeves et al., 1998). Two randomized controlled trials in residential care homes that had exercise promotion and falls prevention interventions, were both able to show improvement in their intervention groups in the short term (McMurdo and Rennie, 1993; McMurdo et al., 2000). One study described the introduction of an oral health training programme for care staff and concluded that despite evidence of need and an increase in care staff knowledge, actual oral care did not improve one week or one year after the intervention (Simons et al., 2000). In contrast to experimental and before and after evaluation designs, other intervention studies have focused on specific conditions such as depression or behavioural difficulties and raised staff awareness, but have not involved nurses. For example, Ames (1990) attempted to treat depression among older residents of 12 residential homes. Psychiatric interventions proved to be difficult to implement and 
there was no evidence to suggest efficacy of the interventions at three months, or after one year. More recently, the randomized-controlled trial by Llewellyn-Jones et al. (1999) evaluated the effectiveness of a population-based multifaceted sharedcare intervention for late life depression in residential care. Although their methods have been criticized (Cameron et al., 2000; Deeks and Juszczak; 1999; Haynes, 1999), they claim there was significantly more movement to 'less depressed' levels of depression at follow-up in the intervention group than in the control group.

Meehan et al. (2002) describe the preliminary findings of a partnership project where a project nurse (not primary care based) using an action research approach, was able to work with nursing and residential care homes to review training and development needs and inform the commissioning of education and services The authors described a range of new intitiatives because of the partnership approach but did not discuss the implications of the changes for the older people. All the intervention studies reviewed relied on extra researchers/ specialists to implement the intervention, did not discuss how existing community services could be used to sustain change, and followed up their interventions for a year or less.

\section{The move into residential care}

Considerable evidence suggests that admission to residential care is often precipitated by a sudden crisis or psychological factors such as loneliness, grief or the lack of companionship that might follow bereavement (Allen et al., 1992; Burholt, 1998; Lee et al., 2002; Warburton, 1994). In particular, the fear of moving into an 'institution' or the lack of involvement older people have had in the decision-making process can constitute a threat to an older person's sense of individuality (Peace et al., 1997). Morgan et al. (1997) suggest that older people who perceive relocating to a care home as stressful, are at risk of developing either physical illness or negative psychosocial states. The focus of nursing research in this area, therefore, has been on the importance of involving and providing continuity of care for the patient and their carer(s) during the transition period and on the maintenance of their sense of self. Hunter et al. (1993) suggested that district nurses and community psychiatric nurses might be best placed to engage older people and their carers in discussions about their care options. Reed and Morgan (1999) interviewed 20 older people and 17 of their family members following discharge from hospital to a care home. They found that few people had been offered opportunities to discuss their move with nurses and that older people tended to adopt a stoical attitude. Nolan et al. (1996) and Reed and colleagues (1996; 1999) suggest how nurses might facilitate such discussion, as well as support older people and their carers through the process of adapting to their new environment. Lee et al. (2002) reviewed 30 years' research into older people's experiences of residential care placement and concluded that although there was evidence on older people's transition to care, less was known about how older people, and particularly those from different ethnic backgrounds, come to terms with residential life. This area of research draws attention to the issues that might face older people prior to, during or following a move to residential care and suggests that nurses could be appropriately placed to undertake sensitive interventions.

\section{Involvement of primary care services}

\section{Primary care nursing involvement: issues of access and demand}

A national survey of access to NHS services by care homes for older people in England (Jacobs et al., 2001) found that almost all care homes had access to district nursing services, but access to specialist nursing support was limited and the frequency of contact care homes had with nursing services was variable. Since 1992, the number of district nursing contacts in care homes offering residential care has risen by $13 \%$, even though actual numbers of older people in residential care are not increasing at an equivalent rate. Older people in care homes consistently account for about $7 \%$ of all district nurse contacts, and the proportion of this population being seen by district nurses is rising as the average age of the resident rises (Audit Commission, 1999). Little is known about the kind of nursing support that residential care homes receive from generalist and specialist community based nursing services. Donald et al. (2002a; 2002b) undertook a census in one county of district nursing involvement in care homes and suggested their work was primarily concerned with wound care and the management of continence. 
However, the census was based on care home managers' responses choosing from a range of six predetermined nursing interventions. This could have meant only a partial account of the range of district nursing work in care homes was achieved. In a study that asked district nurses about working in residential care homes, practitioners described it as a significant part of their work often shaped by factors unrelated to patient need such as, GP attachment, availability of other resources and confusion around their role and responsibilities (Goodman et al., 2003). They acknowledged this was a demanding aspect of their work, but they felt ambivalent about their increasing involvement. The only other study found that has considered nursing involvement surveyed 730 palliative care nursing specialists' work in both types of homes. The authors concluded the work was reactive, intermittent and task specific. There were only a few examples provided where practitioners had adopted a more proactive approach in these settings (Froggatt et al., 2002).

\section{Demand for services}

Counsel and Care (1998) looked at the relationship between health services and care homes. Although the involvement of GPs was central to the study, it is nevertheless remarkable that there is no mention of district nursing services and only very brief discussion of community psychiatric nurse involvement. Crosby et al. (2000) monitored the contacts with primary health care services made by residents in 10 nursing homes, 14 residential homes and three dual-registered homes over a 16 -week period in 1996. As no other contemporary studies have measured demand for all the primary health care services by residents, it is difficult to compare this study. Contacts with the district nursing service were less than with GPs. However, residents in residential care homes placed a high level of demand on district nursing services. Multiple regression analysis indicated that the interaction of several factors explained $60 \%$ of the demand placed on primary care services (Crosby et al., 2000). These were: resident numbers, mean dependency of the residents of the home, number of whole time equivalent (WTE) care staff employed by the home, the mean experience of staff in years and the percentage of WTE care staff who had formal qualifications. A positive relationship was found between $20 \%$ of residential home patients who used a high proportion of primary care services. Crosby et al. (2000) argue that the significant demand on district nursing services from a minority of highly dependent residents raises issues about appropriate placement, the type of care residential home staff are allowed to undertake and the availability of specialist geriatric services.

\section{Discussion: the contribution of primary care nursing}

The research reviewed suggests that older people in residential care homes are a vulnerable population who have a spectrum of health needs amenable to nursing support and interventions from primary care. Despite ongoing concern about the health care provided to residents (Black and Bowman, 1997; Counsel and Care, 1998; Royal College of Physicians et al., 2000; Turrell et al., 1998), the research literature contributes little to an understanding of primary care nursing in residential homes. It appears that although district nurses are the primary care nurses who have regular and increasing contact with older people in residential homes (Audit Commission, 1999; Goodman et al., 2003), their role and contribution has consistently been overlooked. Similarly the contribution of community psychiatric nurses, specialist nurses and practice nurses, or the public health role of health visitors in this setting has not been explored in recent research and reports (Counsel and Care, 1998; Crosby et al. 2000; Royal College of Physicians et al., 2000). The only topic that has been given attention in the nursing literature is that of supporting older people during and after the transition to residential care (Lee et al., 2002; Nolan et al., 1996; Reed and Morgan, 1999; Reed and Roskell Payton, 1996). Standards for good practice in care homes (Centre for Policy on Ageing, 1996; Department of Health, 2002) have concentrated more on the experiences and quality of everyday life for older people rather than on access to or standards of health care. A justified concern that care homes are not seen as mini hospitals but as homes for living in, may help to explain why there has been minimal discussion of older peoples' need, access and use of nursing support and care in these settings. 
Recommendations for the development of intermediate care identify care home settings as service providers, and presuppose a network of support from primary care that is likely to include nursing expertise. Furthermore, the recent NSF (Department of Health, 2001b) on older people indicates that nurses should be involved in providing support and training to care staff. Arguments for specialist gerontological nurses in these settings do not appear to engage with how these practitioners will integrate with existing services nor acknowledge the existing nursing input or potential for development of these services (Royal College of Physicians et al., 2000). It is also unclear why the existing involvement of primary care nursing has been so overlooked when there has been discussion of the demands on GP services, and in some situations, additional remuneration to acknowledge the extra work these providers create for primary care services.

Research on nurses in primary care and district nurses in particular consistently identifies their contribution as maintaining continuity in care, coordinating and involving other services, as well as providing direct and specialist care to a predominately older patient group (Audit Commission, 1999; Goodman et al., 1998; Griffiths, 1996; McIntosh, 1996; Smith et al., 1993). These are attributes that do and could benefit further older people in care homes. The inevitable lack of continuity apparent in intervention-based studies could be addressed by primary care nurses adopting a more proactive role in the management of health care for this population - an approach that reflects a public health dimension of primary care nursing (Department of Health, 2002). It is to be hoped that the introduction of the Single Assessement Process and use of standardized approaches to assessment and review of care (Ford and McCormack, 1999) will encourage a more systematic approach and a greater recognition of the contribution of nursing for this population.

\section{Conclusion}

Much of the literature reviewed in this paper does not make a distinction between nursing and residential home populations. From a primary care nursing perspective the absence of nursing staff in the home defines their involvement with older people as the main providers of nursing support and interventions. Very little is known about how much care is provided, in what context and to what effect. However, what research there is strongly suggests that although older people in these settings have a range of health needs that could be helped by nursing support, their access to primary nursing care is variable. Flicker (2002) observes that although there has been considerable progress in the clinical management of disabling problems, such as dementia, osteoporosis, incontinence and falls, the appropriate mix of funding between primary, secondary and tertiary interventions has not been determined. Arguing from an Australian perspective he argues the health care needs of older people in residential care have been totally neglected. In this country, primary care trusts have the opportunity to take a more strategic, proactive approach and work with public, private and voluntary providers of care for this vulnerable population. This review has demonstrated the need to develop what is currently being offered for older people, ensure equity of access to services and ultimately evaluate which models of care and who is best placed to promote and maintain the health of older people in residential care homes.

\section{References}

Allen, I., Hogg, D. and Peace, S. 1992: Elderly people: choice, participation and satisfaction. London: Policy Studies Institute.

Ames, D. 1990: Depression among elderly residents of localauthority residential homes, its nature and the efficacy of intervention. British Journal of Psychiatry 156, 667-75.

Audit Commission. 1999: First assessment: a review of district nursing services in England and Wales. Abingdon: Audit Commission Publications.

Bagley, H., Cordingley, L., Burns, A., Godlove Mozley, C., Sutcliffe, C., Challis, D. and Huxley, P. 2000: Recognition of depression by staff in nursing and residential homes. Journal of Clinical Nursing 9, 445-50.

Black, D. and Bowman, C. 1997: Community institutional care for frail elderly people. British Medical Journal 315, 441-42.

Burholt, V. 1998: Pathways into residential care: service use, help and health prior to admission. Health Care in Later Life 3(1), 15-33.

Butler, M., Norton, R., Lee-Joe, T., Cheng, T. and Campbell, A.J. 1996: The risks of hip fracture in older people from private homes and institutions. Age and Ageing 25, 381-85.

Cameron, I., Ames, D., Hawe, P., McDonald, I. and White, K.L. 2000: Intervention for late life depression in residential care. British Medical Journal 320, 119. 
Centre for Policy on Ageing. 1996: A better home life: code of good practice for residential and nursing home care. London: CPA.

Challis, D., Godlove Mozley, C., Sutcliffe, C., Bagley, H., Price, L., Burns, A., Huxley, P. and Cordingley, L. 2000: Dependency in older people recently admitted to care homes. Age and Ageing 29(3), 255-60.

Counsel and Care. 1998: Bringing health to homes. The relationship between health services and homes for older people. London: Counsel and Care.

Crosby, C., Evans, K.E. and Prendergast, L.A. 2000: Factors affecting demand for primary health care services by residents in nursing homes and residential care homes. Ceredigion: The Edwin Mellen Press.

Dant, T. 1988: Dependency and old age: theoretical accounts and practical understandings. Ageing and Society 8, 171-88.

Darton, R.A. 1994: Review of recent research on elderly people in residential care and nursing homes, with specific reference to dependency. Canterbury, Kent: Personal Social Services Research Unit (PSSRU), Discussion Paper No. 1082.

Davies, B. and Knapp, M.R.J. 1978: Hotel and dependency costs of residents in old people's homes. Journal of Social Policy 7 , $1-22$.

Deeks, J.J. and Juszczak, E. 1999: Commentary: beyond the boundary for a randomized controlled trial? British Medical Journal 319, 652-53.

Department of Health. 1990: The NHS and Community Care Act. London: Department of Health.

Department of Health. 2000: Community care statistics 2000. Residential personal social services for adults, England. London: Department of Health.

Department of Health. 2001a: Care homes for older people. National minimal standards. London: Department of Health.

Department of Health. 2001b: National service framework for older people. London: Department of Health.

Department of Health. 2002: Liberating the talents. London: Department of Health.

Donald, I., Cope, B. and Roberts, S. 2002a: Nursing and care homes: a census view of care delivery in Gloucestershire Journal of Community Nursing 16(8), 15-18.

Donald, I., Cope, B. and Roberts, S. 2002b: District nursing and care homes - a census view. Journal of Community Nursing 16(8), 14-15.

Flicker L. 2002: Clinical issues in aged care: managing the interface between acute, sub acute, community and residential care. Australian Health Review 25(5), 136-39.

Ford, P. and McCormack, B. 1999: Determining older people's need for registered nursing in continuing healthcare: the contribution of the Royal College of Nursing's older people assessment tool. Journal of Clinical Nursing 8, 731-42.

Froggatt, K., Poole, K. and Hoult, L. 2002: The provision of palliative care in nursing and residential homes: a survey of clinical nurse specialist work. Palliative Medicine 16, 481-87.

Godlove Mozley, C., Challis, D., Sutcliffe, C., Bagley, H., Burns, A., Huxley, P. and Cordingley, L. 2000: Psychiatric symptomatology in elderly people admitted to nursing and residential homes. Aging and Mental Health 4(2), 136-41.

Goodman, C., Knight, D., Machen, I. and Hunt, B. 1998: Emphasizing terminal care as district nursing work: a helpful strategy in a purchasing environment? Journal of Advanced Nursing 28(3), 491-98.

Goodman, C., Woolley, R. and Knight, D. 2003: District nurses' experiences of providing care in residential care home settings Journal of Clinical Nursing 12, 67-76.

Haynes, B. 1999: Can it work? Does it work? Is it worth it? The testing of health care interventions is evolving. British Medical Journal 319, 652-53.

Hunter, S., Brace, S. and Buckley, G. 1993: The inter-disciplinary assessment of older people at entry into long-term institutional care: lessons for the new community care arrangements. Research, Policy and Planning 11(1/2), 2-9.

Jacobs, S., Alborz, A., Hann, M. and Glendinning, C. 2001: A national survey of access to NHS services of older people in residential and nursing care homes. Manchester: National Centre for Primary Care and Research Development Manchester.

Jacobs, S. 2003: Addressing the problems associated with general practitioners' workload in nursing and residential homes: findings from a qualitative study British Journal of General Practice 53, 113-19.

Jagger, C. and Lindesay, J. 1997: Residential care for elderly people: the prevalence of cognitive and behavioural problems. Age and Ageing 26, 475-80.

Kavanagh, S. and Knapp, M. 1998: The impact on general practitioners of the changing balance of care for elderly people living in institutions. British Medical Journal 317, 322-27.

Komaromy, C., Sidell, M. and Katz, J.T. 2000: The quality of terminal care in residential and nursing homes. International Journal of Palliative Nursing 6(4), 192-200.

Lall, B. 1999: A pilot screening programme to assess the dental treatment needs of older people in residential and nursing care. Journal of BASE 68, 19-23.

Lee, D.T.F., Woo, J. and Mackenzie, A.E. 2002: A review of older people's experiences with residential care placement Journal of Advanced Nursing 37(1), 19-27.

Llewellyn-Jones, R.H., Baikie, K.A, Smithers, H., Cohen, J., Snowdon, J. and Tennant, C.C. 1999: Multifaceted shared care intervention for late life depression in residential care: randomized controlled trial. British Medical Journal 319, 676-82.

Mahoney, F. and Barthel, D. 1965: Functional evaluation: the Barthel Index. Maryland State Medical Journal 14, 61-65.

McIntosh, J. 1996: The Question of Knowledge in District Nursing. International Journal of Nursing Studies 33(3), 316-24.

McMurdo, M.E.T. and Rennie, L. 1993: A controlled trial of exercise by residents of old people's homes Age and Ageing 22, 11-15.

McMurdo, M.E.T., Millar, A.M. and Daly, F. 2000: A randomized controlled trial of fall prevention strategies in old peoples' homes. Gerontology 46, 83-87.

Medical Research Council Cognitive Function and Ageing Study (MRC CFAS) and Resource Implications Study (RIS 
MRC CFAS). 1999: Profile of disability in elderly people: estimates from a longitudinal population study. British Medical Journal 318, 1108-11.

Meehan, L., Meyer, J. and Winter, J. 2002: Partnership with care homes: a new approach to collaborative working. NT Research 7(5), 348-59.

Morgan, D., Reed, J. and Palmer, A. 1997: Moving from hospital into a care home - the nurse's role in supporting older people. Journal of Clinical Nursing 6, 463-71.

Nolan, M., Walker, G., Nolan, J., Williams, S., Poland, F., Curran, M. and Kent, B.C. 1996: Entry to care: positive choice or fait accompli? Developing a more proactive nursing response to the needs of older people and their carers. Journal of Advanced Nursing 24, 265-74.

Norton, R., Campbell, A.J., Reid, I.R., Butler, M., Currie, R., Robinson, E. and Gray, H. 1999: Residential status and risk of hip fracture Age and Ageing 28, 135-39.

Pattie, A.H. and Gilleard, C.J. 1979: Manual of the Clifton Assessment Procedures for the Elderly (CAPE). Seven Oaks: Hodder \& Stoughton.

Peace, S., Kellaher, L. and Willcocks, E. 1997: Re-evaluating residential care. Buckingham: Open University Press.

Peet, S.M., Castleden, C.M. and McGrother, C.W. 1995: Prevalence of urinary and faecal incontinence in hospital and residential and nursing homes for older people. British Medical Journal 311, 1063-64.

Peet, S.M., Castleden, C.M, McGrother, C.W. and Duffin, H. M. 1996: The management of urinary incontinence in residential and nursing homes for older people. Age and Ageing 25, 139-43.

Pell, J. and Williams, S. 1999: Do nursing home residents make greater demands on GPs? A prospective comparative study. British Journal of General Practice 49, 527-30.

Personal Social Services Research Unit (PSSRU). 2001: Residential and nursing home care of elderly people. Canterbury, Kent: PSSRU, University of Canterbury Kent.

Proctor, R., Stratton Powell, H., Burns, A., Tarrier, N., Reeves, D., Emerson, E. and Hatton, C. 1999: An observational study to evaluate the impact of a specialist outreach team on the quality of care in nursing and residential homes Aging \& Mental Health 2(3), 232-38.

Reed, J. and Morgan, D. 1999: Discharging older people from hospital to care homes: implications for nursing. Journal of Advanced Nursing 29(4), 819-25.
Reed, J. and Roskell Payton, V. 1996: Constructing familiarity and managing the self: ways of adapting to life in nursing and residential homes for older people. Ageing and Society 16, 543-60.

Roe, B. and Shiels, C. 2000: Focus on continence: survey of care policies. Elderly Care 12(1), 34-38.

Royal College of Physicians, Royal College of Nursing and British Geriatrics Society. 2000: The health and care of older people in care homes - a comprehensive interdisciplinary approach. London: Royal College of Physicians.

Shiels, C. and Roe, B. 1999: Pressure sore care. Nursing Standard 14(6), 41-44.

Simons, D., Baker, P., Jones, B., Kidd, E.A.M. and Beighton, D. 2000: An evaluation of an oral health training programme for carers of the elderly in residential homes. British Dental Journal 188, 206-10.

Smith, P., Mackintosh, M. and Towers, B. 1993: Implications of the new NHS contracting system for district nursing. Journal of Interprofessional Care 7(2), 115-24.

Sturgess, I., Rudd, A.G. and Shilling, J. 1994: Unrecognised visual problems amongst residents of Part III Homes. Age and Ageing 23, 54-56.

Taylor, C. and Hendra, T. 2000: The prevalence of diabetes mellitus and quality of diabetic care in residential and nursing homes. A postal survey. Age and Ageing 29, 447-50.

Turrell, A.R., Castleden, C.M. and Freestone, B. 1998: Long stay care and the NHS: discontinuities between policy and practice. British Medical Journal 317, 942-44.

Wanless, D. 2001: Securing our future health: taking a long term view. London: H.M Treasury.

Warburton, R. 1994: Home and away: A review of recent research to explain why some elderly people enter residential care homes while others stay at home. London: Department of Health.

Wilkin, D. and Jolley, D. 1979: Behavioural problems among old people in geriatric wards, psychogeriatric wards and residential homes 1976-1978. Manchester: Research Report No. 1. Research Section, Psychogeriatric Unit, University Hospital of South Manchester.

Yates, M., Horan, M.A., Clague, J.E., Gonsalkorale, M., Chadwick, P.R. and Pendleton, N. 1999: A study of infection in elderly nursing/residential home and community-based residents. Journal of Hospital Infection 43, 123-29. 